\title{
PASADO Y PRESENTE DE LA AUTORIDAD DEL CORREGIDOR EN EL ESPACIO POLÍTICO Y JURÍDICO INDÍGENA
}

Marcelo Fernández Osco

EL PRESENTE ARTícULO DISCUTE el avance de algunos textos y explora las disposiciones administrativas que remodelaron el cargo del corregidor y permitieron afianzar el Estado en los diversos momentos históricos en el espacio político y jurídico indígena. Se examinan los cambios y continuidades de la perviviente autoridad del corregidor en la larga historia. A través de un enfoque procesual y cronológico, se resaltan sus momentos constitutivos, así como las características distintivas de sus atribuciones jurídicas y políticas, producto de los cambios estructurales.

Iniciamos la discusión sobre la importancia del corregidor de indios en la Colonia no sólo porque expresa el interés político y jurídico de la empresa colonial, sino también porque, en mayor o menor grado, en él se representan antecedentes prehispánicos. Sobre todo cuando su perversa actuación ha sido sometida a la crítica indígena, a manera de caja de resonancia de las aspiraciones y reclamaciones.

En la misma perspectiva se resitúa el análisis de esta autoridad durante la República y hasta antes de la Revolución Nacional de Bolivia de 1952. Si bien en este período no tuvo el mismo nivel 


\section{MARCELO FERNÁNDEZ OSCO}

jerárquico que en la Colonia, su actuación perfilaba los polos extremos de indios y no indios, principalmente el esencialismo de la conducta colonial. La muestra más clara de lo sostenido son precisamente las distintas sublevaciones indígenas, las cuales se hallan ligadas entre sí casi de manera connatural.

Finalmente, después de la Revolución Nacional, a efecto de las reformas populares impuestas, la autoridad del corregidor se encuentra en una nueva crisis. A diferencia de las anteriores experiencias, pervive su institucionalidad, pero no necesariamente sus actores. Se encuentra en un proceso de democratización, lo cual dependerá mucho de las circunstancias histórico-locales y regionales. Unos se encuentran en la disyuntiva de acelerar el proceso de liberación de los poderes despóticos, adscribiéndolo a su propia perspectiva de poder, en un franco proceso de comunalización. Los otros toman el camino ambiguo de remozarlo, como una vía para lograr su pertenencia a la cultura nacional, de la que fueron separados históricamente.

\section{ANTECEDENTES COLONIALES}

\subsection{Constitución de la autoridad}

En general, en América el corregimiento tiene un claro precedente hispánico y también prehispánico. Durante el incanato, era similar a los corregidores aquella autoridad conocida con el nombre de jues michoc. Él tenía residencia en vastos territorios semejantes a las provincias de la Colonia y bajo su jurisdicción se encontraba variable número de "principales". Su misión más importante era administrar "buena justicia y no rrobaua ni tenía tratos y contratos ni ocupaua en texer y traxenear nadie se quexaua de ellos... temía a Dios y a la justicia y castigos en todo el rreyno" (cf. Waman Puma de Ayala 1992/1614: 111, 186, 206, 249, 349).

Su institucionalización en los reinos de Indias, en parte, se ha inspirado en el mismo antecedente hispánico que para los indígenas representaba la versión nefasta del tocricoc (Waman Puma de Ayala 1992/1614: 313). Una de las autoridades responsables de aplicar sentencias según las ordenanzas y la ley incas; especialista en la 


\section{PASADO Y PRESENTE DE LA AUTORIDAD DEL CORREGIDOR}

gestión de las instituciones y la organización política, judicial y militar de su imperio.

Desde la óptica estrictamente colonial, según refiere la literatura pertinente (cf. Muro Orejón 1989; Lohmann Villena 1957; Bayle 1945), la institución del corregimiento ha tenido características de gobierno local. Su función era el control de los abusos entre las poblaciones realengas, centrado en la tarea de "corregir las tropelías y volver a implantar la justicia" (Muro Orejón 1989: 216). Precisamente, en virtud de ello se conocía esta autoridad como "juez corregidor", que asumía el poder policial del monarca o rey.

Hasta antes del implante de los corregimientos, sus funciones eran asumidas por los obispos, los mismos que, bajo el rótulo de "protectores de indios", tenían la primordial obligación civilizadora, principalmente a través de la evangelización, así como de administración o fiscalización de la actuación de autoridades como los encomenderos, quienes solían extralimitarse en sus atribuciones. Esto último, merced a que los indios eran considerados bajo la trilogía de "miserable", "menor" y "rústico" y, consiguientemente, era absolutamente imperativo imprimir políticas de tutelaje, protectorado, defensa y administración de las buenas costumbres (cf. Lohmann Villena 1957: 31-43; Bayle 1945: 24-45).

Como es bien sabido, el Estado colonial, para ejercer efectiva dominación, desde sus inicios fue organizado en una república de españoles y otra de indios. Esta estructura dicotómica suponía también instituir dos sistemas de autoridades. Si bien las estructuras jerárquicas, como los virreinatos, eran compartidas, el nivel regional o local era gobernado en el esquema de repúblicas; con clara supremacía y jerarquía del corregidor de españoles sobre el corregidor de indios.

Una profusa literatura nos da cuenta de que la institucionalidad del corregidor de indios en el virreinato estuvo mediatizada por una serie de tensiones, acuerdos y desacuerdos. Es así que en 1558 el licenciado Lope de Castro era uno de los artífices para su creación, en el marco de dotar de directivas específicas que aportaran al control de la población indígena. Sin embargo, más tarde hubieron de suscitarse opiniones adversas a esta autoridad, sindicándolo como "polilla de la República" (Lohmann Villena 1957: 56), justamente 


\section{MARCELO FERNÁNDEZ OSCO}

por una serie de incompatibilidades en su función, como entre el doctrinero y el corregidor. Consecuentemente, estaban siendo cuestionados los intereses de los encomenderos tanto como los de los corregidores españoles. A ello se sumó el argumento de su sostenibilidad económica, lo eual representaba su talón de Aquiles.

Empero, en esta discusión estuvo también presente el virrey Francisco Toledo (1568-1578), mostrándose titubeante y vacilante al principio, hasta que decide la confirmación definitiva bajo ciertos juicios empíricos. Casi en todo el proceso colonial la autoridad del corregidor de indios fue un espacio de serias controversias, tanto entre las autoridades coloniales como entre el mundo indígena. Sin duda, el momento más crítico de supresión de los corregidores fue a fines del siglo XVIII, pues en 1784 se decreta la muerte del corregimiento y el advenimiento de la creación de las intendencias, a efecto de prácticas expoliatorias y prejuicios causados a la industria, como el mal uso y mengua de las recaudaciones de tributos indígenas, y fundamentalmente por la práctica ilegal del reparto de mercancías, lo que suscitará las rebeliones indígenas de Túpac Amaru y Katari (cf. Del Valle...; Thomson 1996a y b).

En síntesis, podemos sostener que la autoridad del corregidor representa el despótico y centralizado poder colonial, aunque nominalmente debía ser sujeto de mucha prudencia y entereza.

\subsection{Competencias}

En principio, fueron los "jueces de naturales" los que tenían la tarea de administrar justicia en asuntos civiles de cuantía inferior, a cincuenta pesos, y de ello, sumariamente, en juicios orales. Nada entendían en materia penal, militar o política. Sólo con la instauración de los alcaldes pedáneos, en primera instancia, hubieron de conocer de los litigios menudos en el ámbito civil y criminal (cf. Lohmann 1957: 25-34).

Con su legalización, tenían la función de administrar justicia, tanto en lo civil como en lo penal, bajo el referente de la legislación positiva colonial. Portaban la vara de justicia a partir de tres principios: facilidad, brevedad y gratuidad; todo en el marco del trámite sumarial, evitando posibles perjuicios a los indios. Estaban limitados de aplicar 
sanciones como la pena capital o mutilación de miembros (Idem: 257), pero no así de ejecutar hasta un centenar de azotes o treinta pesos, conocido en el léxico de la actual justicia indígena como un quintal de azotes -una de las penas de mayor cuantía practicadas clandestinamente-, cuestión que se tratará con mayor detalle más adelante.

Formalmente estaban limitados de facultades legislativas, pero en la práctica imponían sus apetitos personales de lucro en cuanto les fuera posible. Eran los primeros en el monopolio del comercio y el tráfico de influencias, así como en la corrupción de la administración de justicia, o complicando las demandas por justicia (cf. Bayle 1945).

Su actuación jurídica era oficialmente revisada por el corregidor de españoles, como instancia de apelación y ejecución de mandatos que ésta representaba, una limitante que no le obstaculizaba para seguir siendo la expresión máxima del poder del Rey dentro de su demarcación territorial, es decir, que, no obstante dicha hegemonía, las autoridades indígenas regularmente administraban justicia en su propia lógica, ligada al culto a los ancestros momificados, que aún estaba vigente (cf. Salomón 1990: 148-163).

Los corregidores de indios eran investidos por el virrey, por temporadas de variable duración, entre cinco, tres, dos y un año (cf. Sarmiento Donate 1988; Bayle 1945: 127). Sus salarios habían sido señalados a costa de los indios; precisamente este principio nos explica el porqué de las actuaciones perversas y anómalas de los corregidores, aunque las jerarquías coloniales originalmente concebían como "modelo vivo o dechado de conducta, cristiandad y rectitud que debían imitar los indios" (Lohmann 1957: 234).

Entre sus funciones se contemplaba el presenciar la repartición de tierras, practicada por las autoridades indígenas, supuestamente imponiendo el criterio de justicia distributiva. Igualmente, velar por la moralidad pública, sancionando la prostitución ${ }^{1}$ y promoviendo el progreso de las obras públicas.

${ }^{1}$ Según Waman Puma de Ayala, los corregidores, junto con otras autoridades de menor rango, eran los principales artífices del quebranto de la moral pública, ya que andaban "rondando y mirando la güergüenza de las mujeres casadas y doncellas $y$ hombres prencipales. $Y$ andan robando sus haziendas $y$ formican a las cazadas y a las doncellas las desuirga. Y ací andan perdidas y se hazen putas y paren muchos mesticillos y no multiplica los yndios" (1992/1614: 508). 


\section{MARCELO FERNÁNDEZ OSCO}

Para los procesos de administración de justicia, tanto civiles como criminales, estaba obligado a recurrir a los intérpretes. Se designaba un actuario como requisito protocolar de toda diligencia judicial y procesal, así como para la adecuada sustanciación de los procesos.

Los corregidores, en general, además de cumplir la función de gobernador, eran al mismo tiempo "capitán general" (Recopilación de Leyes de los Reynos de las Indias MDCCXXXXI: 117). Asumimos que esto también fue extensivo a los corregidores de indios. Aunque en el interior de las provincias no era frecuente el movimiento de cuestiones militares, al amparo de esta prerrogativa se desarollaban acciones militares de baja intensidad, centradas en el violento esquema policial, por lo que cada corregidor "debía tener siempre armas y cabalgaduras prevenidas" (Lohmann 1957: 264) para cumplir con situaciones de persecución. Al respecto, son elocuentes las representaciones gráficas de Waman Puma de Ayala al denunciar las penurias y vejámenes a los que fue sometido don Cristóbal de León sólo por defender a los indios de su provincia, o los crueles castigos a los que fue sometido el alcalde ordinario por resistirse a satisfacer dos huevos al corregidor; consecuentemente, por tales arbitrios se los caracterizó como autoridades que no "temen a Dios ni a la justicia. Destruy y rroba y castiga cruelmente cin ynformación de derecho, uencido por fuero y derecho de justicia" (1992/1614: 500 y 504).

El corregidor fue una autoridad con jurisdicción territorial. Su residencia se fijaba en la provincia ${ }^{2}$-según la terminología de la época-, en una de las poblaciones principales: la marka, el microcosmos territorial indígena compuesto por una estructura compleja de ayllus y parcialidades. Como autoridad política que era, estaba encargado de mantener el imperio de las leyes y el Estado de derecho, aplicando con todo rigor la legislación y las ordenanzas expedidas para conservar el orden público (cf. Sarmiento Donate 1988).

2 Según Lohmann, Toledo trazó una nueva distribución del territorio, dividiéndolo en 71 provincias, que eran 614 repartimientos (1957: 89). 


\section{PASADO Y PRESENTE DE LA AUTORIDAD DEL CORREGIDOR}

El implante de estos nuevos esquemas político-administrativos constituyó el inicio del proceso de fragmentación territorial prehispánico, práctica que no termina aún, pues ello supuso la concentración de la población indígena en "concierto y policía" (véase Sarmiento Donate 1988: 178), iniciada en la época del marqués de Cañete y perfeccionada por el virrey Toledo; todo para facilitar el (des)gobierno de los indios mediante la Ley Evangélica.

Las autoridades indígenas quedaron de facto bajo la tuición del corregidor, lo cual implicaba la reducción de su campo de actuación, que debía circunscribirse sólo a la recolección de tributos, con arreglo a los padrones o la institución de los alcaldes de indios. Ello para facilitar diligencias oficiales tanto como para desestructurar el sistema de autoridades indígenas, fomentando de ese modo las actividades ilegales y clandestinas que, en palabras de Waman Puma de Ayala, se conocen como el "mundo al revés".

Nominalmente, otra de sus funciones administrativas era el aconsejar a los indios sobre la adquisición de bueyes o mulos, de manera de fomentar la producción agropecuaria, así como supervisar y vigilar el comercio de los trajinantes (cf. Recopilación de Leyes de los Reynos de las Indias MDCCLXXXXI. Tomo II: 120).

Sostenemos la tesis de que el Cabildo, tanto en las jurisdicciones españolas como indígenas, permitió estructurar la actual asamblea comunal, conocida también como jach'a justicia (Fernández 2000), en virtud de que este espacio era un organismo colegiado de vecinos y encomenderos residentes en la población principal. Una tradición que subsiste entre las actuales comunidades, ayllus o markas andinas, donde se discute y resuelven temas vitales.

\subsection{Crisis de la autoridad}

En sus orígenes, así como en el proceso histórico, la autoridad del corregidor de indios se erige en la desconfianza y la controversia, pues, los corregidores de indios eran los más encarnizados expoliadores e infligían molestias y perjuicios con todo género de caprichos e industrias. 
Precisamente por lo perverso de este gobierno, en especial con el mundo indígena, entre otros, fue tema de debate vivo y enconado y "no tuvo tregua hasta que en 1784 se le dio el golpe de gracia con la creación de las Intendencias" (Lohmann 1957: 404). Al respecto, Waman Puma de Ayala dedica sendos capítulos a la administración de los corregidores, listando desde "la primera historia de ellos, don Diego de Avendaño", calificándolo como "señores apsolutos con poco temor de Dios y de la justicia", y que fueron declarados enemigos de los caciques principales y de la población indígena, como la viva representación de "Luysber... prínsipe de las tinieblas...", siempre deudor de trabajos, servicios y comidas, que castiga a los defensores de los indios, como sucedió con el principal Cristóbal de León, quien fuera sometido al castigo del cepo y amenazado con el trabajo en las galeras. De igual forma, las autoridades reticentes a las prebendas eran castigadas cruelmente, sin respetar fuero ni derechos. La gráfica más explícita del desgobierno es, sin duda, el hábito de rondar "y mirar la güergüenza"de las mujeres, sin que por ello medie justicia alguna. En este aspecto se describen prácticas de corrupción y de negociación de la ley; tampoco son menos importantes las constantes prácticas de expropiación de tierras y bienes, frente a cuyo proceso el referido autor recomienda el colocado del siguiente aviso: "temed, cristianos, a Dios y a la justicia, y no tengais soberuia y no llaméys a la justicia para que séays castigado" (1992/1614: 491 al 519).

La rebelión indígena de 1780, según los estudios especializados de O'Phelan Godoy (1976) y Golte (1980), se suscitó por el agotamiento del modelo colonial; principalmente por el abusivo comercio mercantil de reparto de efectos entre la población indígena. Frente a las demandas del Estado y del corregidor gravitaron protestas, evasiones y resistencia.

Por su parte, Thomson (1996a) esgrime la tesis de que los corregidores se hallan estrechamente ligados a las variadas formas de exacción y reacciones indígenas a los abusos del sistema colonial. El punto más alto de este proceso es precisamente la rebelión de Katari, a principios de 1781.

En 1789 "el Virrey Croix aboga por su reposición como el único remedio para hacer frente al desbarajuste provocado por la 
creación de los Intendentes" (Lohmann 1957: 418). Pese a su opinión, estaba decretada la eminente desaparición del corregidor, que también implicó la crisis de la elite indígena de los caciques.

\section{LA REPÚBLICA}

\subsection{Constitución de la autoridad}

Con la misma creación de la República, aparece la autoridad del corregidor. Es connatural al implante del nuevo modelo de división político-administrativa tomado del sistema español, tal como lo refiere el Art. $1^{\circ}$ de la Ley No 28, de 21 de diciembre de 1825: "Los tribunales de justicia, la forma de proceder se sujetarán a la ley de las Cortes españolas de 9 de octubre de 1812" (Iturricha 1909). Es decir, que las antiguas intendencias se convierten en departamentos, los corregimientos en provincias y los cantones vienen de las antiguas parroquias, cuya población oscilaba entre tres a cuatro mil almas. Precisamente en ese último esquema, el corregidor es una extensión del poder estatal supeditado a la jurisdicción del gobernador como máxima autoridad de cada provincia.

Según las distintas constituciones de la temprana República, como la de 1826, 1831 y 1834, los corregidores eran nombrados en los mismos cantones y de acuerdo a su reglamento particular, con la duración de cuatro años en ejercicio de "ciudadanía" 3 y como agente inmediato del subprefecto. A partir de la CPE de 1831 se instituyen los "alcaldes de campaña", que son una especie de "auxiliares" o "policía de seguridad" en cada cantón, directamente supeditados a la autoridad del corregidor (ver Ley de Organización Política 1903). Es probable que con este nivel de autoridad, de "alcalde", haya emergido el actual "corregidor auxiliar", un tipo de autoridad que se ha popularizado desde la revolución de 1952, sobre todo en aque-

${ }^{3}$ La Constitución política del Estado de 1826 , en su capítulo $2^{\circ}$, Art. 14 , estipulaba: "1० Ser boliviano. $2^{\circ}$ Ser casado o mayor de 21 años. $3^{\circ}$ Saber leer y escribir; bien que esta calidad sólo se exigirá desde el año $1836.4^{\circ}$ Tener algún empleo o industria, o profesar alguna ciencia o arte, sin sujeción a otro en clase de sirviente doméstico". 


\section{MARCELO FERNÁNDEZ OSCO}

llos ayllus o markas que cuentan con extensos territorios. No obstante, tales autoridades no existen ni se las asume o nombra como tal en la norma estatal.

Sólo a partir de la Constitución política del Estado (CPE) de 1839 , se determina que "se renovarán cada año" y son asumidos como "funcionario público" (Art. 125). Al igual que los cargos de alcalde, y a diferencia de las otras autoridades de jerarquía mayor, "son un servicio a la patria; y ningún ciudadano sin causa justa podrá eximirse de desempeñarlos" (CPE 1931, Art. 137). Lo que quiere decir que no son remunerados por el Tesoro General de la Nación, al igual que en la Colonia, obligando a ejercer formas de coacción prebendales y de despotismo.

Durante el Gobierno del mariscal Santa Cruz desaparece el corregimiento de las capitales de departamento (cf. Reglamento de Ordenanza Política 1903), en virtud al desarrollo y especialización del control policial, y no así de las poblaciones indígenas, donde perdura hasta la actualidad.

\subsection{Competencias}

Grosso modo, para el cargo de corregidor hubieron de mantenerse aquellas competencias coloniales a nivel jurídico, político y económico, no su jurisdicción territorial, que pasó a supeditarse al menos a tres niveles suprajerárquicos: el subprefecto, el gobernador y el prefecto. Ante la desaparición del cacique gobernador, pasó a tener tuición directa sobre las autoridades indígenas $\mathrm{u}$ originarias.

Según el Reglamento de Organización Política, entre las principales funciones del corregidor estaban el recaudar las contribuciones e impuestos, vigilar la actuación de los alcaldes parroquiales en lo que toca a administración de justicia, así como ejercer la función policial de seguridad.

Por Ley No 40 del 23 de enero de 1826 (ver Iturricha 1909), se le instituyen competencias en "los juicios de conciliación, en demandas verbales sobre injurias leves, en que no haya de procederse por escrito, y sobre negocios de interés que no pasen de 50 pesos". Empero, la CPE del mismo año, con el Art. 138, intenta controlar sus atribuciones, destinándolo a "mantener el orden y seguridad 
pública, con subordinación gradual al gobierno supremo". Aunque nominalmente, según el Art. 139, le estaba prohibido todo conocimiento judicial, frente a la ausencia casi generalizada de los jueces en el amplio territorio de los ayllus, markas y comunidades, los corregidores asumían competencias judiciales frecuentemente, con excesos de autoridad y acciones locales de carácter represivo, tal como puede confrontarse en los diferentes expedientes históricos.

En las primeras épocas de la vida republicana podemos advertir dos tendencias sobre la actuación de los corregidores. Según nos muestra Medinacelli (1986), en el siglo XIX, en la provincia de Omasuyos, del departamento de La Paz, estas autoridades se asumían y adscribían a la ritualidad y lógica de los antiguos caciques de pueblos. Esto, por el mismo hecho de que los decretos bolivarianos habían abolido a los caciques. Sólo posteriormente, con la Ley de Ex Vinculación de 1874 y la Revisita de 1881, durante el proceso de expansión terrateniente, se convierten en aliados e instrumentos de los viejos y nuevos terratenientes, constituyéndose en parte de la punta de lanza de agresión a los ayllus. En este panorama se pueden explicar los distintos levantamientos armados y legales, como la rebelión de Zárate Willka de 1899 (ver Condarco 1965) o la lucha legal de los caciques apoderados durante las tres primeras décadas del siglo XX (ver Thoa 1984), basadas en la exégesis de los antiguos títulos coloniales (ver Fernández 1996).

En efecto, frente a la consolidación de las haciendas, hubo episodios cruentos, como la rebelión de 1920, en Taraqu (Mamani 1991: 72), aprovechando la derrota del Partido Liberal y la asunción del nuevo régimen republicano. En este ayllu de la marka Waqi (Guaqui), como el sector más afectado por la hacienda, se organizó un primer experimento de reconstitución de comunidad originaria, en cuyo proceso se cuestionó la gestión del corregidor, de tendencia liberal, pero que apoyaba al candidato de la emergente corriente política republicana, a efecto de revertir la avanzada terrateniente. En el fondo, independientemente de su color político, seguía expresando la tradición de "la pax de los colonizadores" (Rivera, en "Prólogo" a Mamani 1991: 5) y la cultura de los vicios procedimentales, o la doble moral de la ley estatal. 


\section{MARCELO FERNÁNDEZ OSCO}

Es el caso del corregidor Cerruto, un mestizo de pueblo del ayllu Taraqu que, tras su nombramiento, a principios de la década de 1920, se inclina por la causa de la restitución comunaria. Instrumental adición por la que el corregidor Cerruto llegó a motivar gran controversia en las altas esferas de la oligarquía y la elite políticas, lo que le costó su inmediata destitución del cargo y su cambio por otro de su misma condición social -un tal Sillerico-, incondicional de un prominente terrateniente de la región. Tras haber emitido desfavorables informes, a través de una comisión, contando con el predefinido accionar del intendente de la policía de Waki, así como de la prefectura: "la comisión que ha sido encomendada y deje constancia del porqué hasta la fecha continúan sublevados los indios, por qué no cumplen con las resoluciones dictadas por el Ministerio y la Prefectura, y si es verdad que los vecinos y el mismo Corregidor de Taraqu mantienen esa sublevación" (ALP - EP 1922). Frente a lo cual, el corregidor cuestionado alegaba: "(mis actos se encuentran) en el marco de la corrección en cumplimiento de mis deberes... y a la ley y también por haber cumplido órdenes y disposiciones superiores cuyo incumplimiento, injusticia me habría traído serias y merecidas responsabilidades" (Idem).

En este proceso, las representaciones indígenas se mostraron proclives en favor del corregidor destituido, argumentando que Sillerico, "lejos de ser un padre o protector es más bien un verdugo, poniéndose al servicio de quienes quieren causarnos todos los males posibles. Este Sillerico ha sido el que en los últimos días ha ocasionado todas las extorsiones y abusos a los indígenas, habiendo engañado aun a las autoridades" (Idem, énfasis propio). Nótese que los indígenas, si bien tienen una concepción de la autoridad del corregidor anclada en la visión clerical y civilizatoria de protectorado, propia de la Colonia, también asumen su horizonte prehispánico de padre. Sobre todo con aquellas autoridades que, independientemente de su filiación política o de casta, se comprometen con los intereses y la causa indígena.

Estos cambios de gobierno a menudo suscitaban evidentes vacíos de poder que fueron aprovechados por las poblaciones indígenas asediadas por la política de ex vinculación y el autoritarismo de los terminales del poder estatal. Intentaban explicitar sus reivindi- 
caciones sugiriendo el cambio de los antiguos corregidores o, en el mejor de los casos, el nombramiento fugaz entre sus propios representantes. Así sucedió con el proceso de la masacre de Jesús de Machaqa, en 1921: en un cabildo comunal fueron nominadas las autoridades - vecinos: "corregidor, jueces parroquiales, agentes cantonales y un brujo hechicero para sus brujeríos con título de cura" (ALP-EP 1921, citado en Choque y Ticona 1996: 50). Mas estos hechos sólo fueron parte del efecto del mismo fenómeno, ya que este movimiento regional subversivo acabó con la muerte del entonces corregidor Estrada en manos de los comuneros, además de una serie de hechos en contra de la población blanco-mestiza pueblerina con antecedentes de maltrato a los comuneros. Únicamente se pudo librar el cura párroco, por el hecho de haber pedido "perdón" por los posibles vejámenes que hubiera cometido para con los indios. Esta acción de "perdonamiento", que en aquella época fue entendida como una manifestación de "respeto por su párroco" (Choque y Ticona 1996: 62), en nuestra lectura tiene directa relación con uno de los preceptos jurídicos indígenas: a la sola muestra de arrepentimiento y pedido de perdón a la comunidad, comprometiéndose a no reincidir en el futuro con la mismas conductas antijurídicas, el infractor puede ser absuelto de las máximas sanciones, como la pena de muerte, entre otros (ver Fernández 2000: 224).

Otro elemento destacable es la condición social de los corregidores. Durante la República, ese cargo era ejercido en la mayoría de los casos por los mestizos vecinos de pueblo, que representaban la última categoría social de la oligarquía dominante, muy a diferencia de la Colonia, cuando los mestizos tenían alta legitimidad frente a los españoles y a la Corona, y sus atribuciones eran más amplias. Sin embargo, su similitud radica en que, tanto en la Colonia como en la República, están ligados a las sublevaciones, al despotismo y a la discriminación racial.

En consecuencia, la autoridad del corregidor sintetiza las contradicciones neocoloniales o "contradicciones no cotáneas", a decir de Bloch (1971); representa la continuidad de la cadena de agresiones de tipo colonial sobre la que se sustentan los poderes oligárquico-liberales. 


\section{MARCELO FERNÁNDEZ OSCO}

\subsection{Crisis de la autoridad}

El implante de la división político-administrativa y sus respectivas autoridades, como el Corregimiento, tuvo un impacto transformador en la medida en que togró desestructurar las unidades territoriales de los ayllus y markas. Este proceso encontró su punto más alto en las primeras décadas del siglo XX, cuando los caciques apoderados exigieron todos unánimes que se practicara "una revisión general de límites" (Rivera 1991) entre ayllus y haciendas, e incluso una revisión total de los límites administrativos entre cantones, provincias, departamentos y hasta del territorio nacional, debido a la incapacidad de la nueva elite gobernante de preservar los originales límites territoriales del país 4 . Ello implicaba retornar a los linderos explicitados por el virrey Toledo; o sea, una revisión general de límites. Al mismo tiempo, se iba produciendo la restitución de las antiguas estructuras de autoridad indígenas que, desde la temprana constitución de la República, se habían ido reduciendo a efecto de la proliferación de nuevas unidades administrativas, así como del implante de la condición de "ciudadano".

Indudablemente, con la cancelación de la institución del cacicazgo por los decretos bolivarianos, el sistema de administración de justicia había sido cooptado y distorsionado por las autoridades estatales. Es así que, en las unidades locales a cargo del corregidor, la administración de justicia se procesaba en base a la dialéctica de culpabilidad, inocencia y castigo, cuando en el ámbito indígena se regía por la reconciliación (cf. Fernández 2000: 53). Por estas y otras razones, el Corregimiento se constituyó en un espacio de confrontación y lucha política.

En esa perspectiva, en 1932, los indios de Jesús de Machaca reeditan aquella experiencia de 1921, nombrando como su corregidor a Esteban Surculento, en el marco más amplio de la propuesta de la "República del Qullasuyu", de Nina Qhispi, que no era otra cosa que una refundación de la República y el respeto de los derechos políticos ancestrales (ver Mamani 1991: 139-153). Ello signifi-

${ }^{4}$ Se referían a las pérdidas territoriales del litoral, en 1879 con Chile; el Chaco, en 1932 con Paraguay; y las tierras de la Amazonía, con Brasil. 
caba que las estructuras administrativas y políticas estaban sumidas en una profunda crisis que demandaba la urgente necesidad de transformar Bolivia en una sociedad plural, así como la ruptura de ese nexo colonial de opresión de una minoría sobre la mayoría.

\section{Posrevolución nacional de 1952}

\subsection{Constitución de la autoridad}

En términos generales, la división político-administrativa implantada desde 1826 no ha cambiado con la revolución nacional de 1952. Por consiguiente, la relación Cantón-corregidor se mantiene, pero con consecuencias desestructuradoras fatales en las unidades político-administrativo indígenas. Es así que hasta 1996 se habían creado 1384 cantones, lo que equivale a decir la misma cantidad de corregidores, de cuyo total, el 51\%, representando 703 cantones, fueron creados a partir de la revolución nacional. En efecto, la autoridad del corregidor sigue siendo un último esfuerzo de eslabón de la presencia estatal en las comunidades, suscitando forzados procesos de cambio político. Sin embargo, en algunas regiones se popularizan paulatinamente, sin que sus competencias legales o políticas sufran variación alguna, porque aún obedecen al principio de gobierno centralizado y unitario.

Según la CPE de 1961, en su Art. 108, los corregidores son extensión político-administrativa del gobierno departamental en la jurisdicción del cantón, retomando el mismo principio las constituciones posteriores, entendiéndose que no se suscitan mayores transformaciones en cuanto a competencias y atribuciones.

Empero, desde la praxis y visión indígenas, el corregimiento sufre un variado y paulatino proceso de transformación a raíz de la revolución de 1952. En unas regiones, como los departamentos de La Paz y Oruro, se comunalizan aquellos espacios de poder otrora controlados por criollos y mestizos en las capitales de provincia y de cantón, hasta incorporarlos dentro de los propios sistemas de autoridades originarias o campesinas. Aquel corregidor que desde sus orígenes había sido un instrumento del control social y político dominantes, y por tanto ilegítimo, ahora pasaba a ser legitimado como 


\section{MARCELO FERNÁNDEZ OSCO}

parte del poder indígena, cabeza de su sistema de autoridades, en la medida en que asume el cargo bajo el principio de rotación y servicio a la comunidad, y sobre cuya base también el Estado termina legitimándolo. Mas en otras regiones, como el departamento de Potosí, el cargo permanece en manos de los vecinos de pueblo, pero bajo conductas más tolerantes.

\subsection{Competencias}

El corregidor es la autoridad nexo entre los distintos niveles de justicia indígena, conceptuada en otro de nuestros trabajos como "justicia mayor y justicia menor" (Fernández 2000), así como el punto de articulación entre el Estado y las comunidades originarias y campesinas.

Si bien desde el formalismo de la ley estatal tiene competencias limitadas, desde la cosmovisión indígena, por un acuerdo tácito, tiene competencias políticas, administrativas, económicas, territoriales y jurídicas, por cuyas características se constituye en la máxima instancia de apelación de la justicia indígena, principalmente para aquellos delitos de menor cuantía, pero también se asume como cabeza de la "justicia mayor", entendida como los delitos graves de impacto comunal.

Para una comprensión cabal de las competencias del corregidor, y a manera de contrapunto, vamos a acudir a algunas experiencias investigativas.

En el cantón Yaku, de la provincia Loayza, del departamento de La Paz, el corregidor es la máxima instancia de autoridad y apelación nombrada en una asamblea comunal. El cargo se rige por el principio ancestral de rotación y servicio, y tiene duración de un año. La persona nombrada debe habilitar su "despacho" u oficina en su propio domicilio, lo cual nos sugiere que el poder camina entre los pobladores y no se halla centralizado, como sucede en la lógica estatal.

Para administrar justicia, a modo de jurisprudencia, utiliza un "libro de actas" que va circulando entre las autoridades salientes y entrantes. Ahí se inscriben los distintos casos que le corresponde atender, como denuncias, transacciones, reuniones entre autorida- 
des y con la comunidad, visitas de autoridades estatales, ceremonias rituales, solución de conflictos, transgresiones a cultivos, compromisos y toda actuación jurídica del ayllu.

Los delitos son sancionados según su tendencia y envergadura, aplicando la premisa de que "a los culpables hay que sancionarlos con justicia, según la falta" (Tomas Colque, Ayllu Mikaya). A efecto de demostrar culpabilidad o inocencia, se permite la utilización de testigos de cargo, documentos $\mathrm{u}$ otras pruebas de antecedentes personales o familiares. En caso de ambigüedad o sospecha de culpabilidad, se somete a la persona infractora al "ámbito sacro" de la justicia, lo cual consiste en su juramentación en la iglesia o en el cementerio, en presencia de las deidades católicas y prominencias ancestrales, como son las wak'as, o las "almas", representadas por los t'uxlus o calaveras; conducido ceremonialmente por un yatiri o sabio espiritual.

Dos elementos que frecuentemente se repiten en los procedimientos de resolución de conflictos son las "multas" y las "actas de buena conducta". Hasta hace aproximadamente 20 años atrás, aún se aplicaba la pena de muerte por cuestiones de delito mayor, como el robo o el asesinato. Pero, por influencia de distintos principios universales, como los "derechos humanos", esto se ha redefinido, sustituyéndolo por la aplicación de sanciones económicas, equivalentes al costo de un buey o, en su defecto, la renuncia a una o más de sus parcelas.

En el fondo, este nivel de autoridad, tanto como el de las otras autoridades originarias, habrá de buscar la conciliación y la integración de la persona a la sociedad y no así la punición del delito como tal, pues supondría el aislamiento social del infractor. Aun en caso de delito mayor, éste tiene que ser afrontado en la convivencia y la cotidianidad. En lo posible, las sentencias no se dictan por la voluntad unilateral del corregidor, sino que son fruto de consultas con las demás autoridades o ex autoridades.

En última instancia, cuando las partes en controversia se enconan, se puede pedir la intervención de otras autoridades estatales de mayor jerarquía, como el subprefecto. Sin embargo, ello no debe entenderse como incapacidad jurídica o falta de competencia sobre el asunto, sino como un "auxilio coercitivo" (Fernández 2000: 


\section{MARCELO FERNÁNDEZ OSCO}

177). Del mismo modo, a solicitud de alguna de las partes, el caso también puede ser declinado a ámbitos estatales, pero en estos estrados judiciales la sanción se explicitará para ambas partes, en la medida en que deben incurrir en gastos económicos tanto el demandado como el demandante, debido a los procesos contenciosos que deben sostener, característicos de la justicia estatal.

Según Rasnake, para los kuraquna de Yura, del departamento de Potosí, el cargo de corregidor, como máxima autoridad, todavía se encuentra en manos de los vecinos. Su actuación se halla enmarcada en aquellos resabios de conducta colonial y neocolonial republicana, resolviendo querellas civiles o criminales, aplicando multas por expresa voluntad personal y castigando en algunos casos con trabajos obligatorios en lugares públicos del pueblo o, en su defecto, en tierras de su propiedad. En cambio, las autoridades originarias se limitan a "aconsejar cómo comportarse mejor" (1989: 83). Frente a esta supuesta controversia, el ritual y los símbolos son utilizados creativamente, como medios y espacios de reelaboración y formulación de nuevas formas sociales o nuevas maneras de entender el mundo, cumpliendo un "papel contestatario en la lucha por el poder y contra la opresión" (Idem: 192). Es decir, que en esta región nos encontramos frente a una cuasi experiencia colonial, con la diferencia de que los yuras explicitan formas de resistencia pasiva desde el mundo ritual-festivo.

Por su parte, para Frías (2002), en Calcha, también del departamento de Potosí, los cargos de corregidor, juez de mínima cuantía, registro civil y notario electoral continúan en manos de las autoridades-vecinos, o sea, de la elite urbana local. El corregidor posesiona a las autoridades tradicionales; también dicta las normas y la actuación de las mismas, que comienzan por cumplir los trabajos públicos en el pueblo. Consecuentemente, se sugiere que la administración de justicia es voluntad unilateral del corregidor, quien aplica sanciones en tanto toleradas por la población indígena.

Tradicionalmente, es el mayor responsable de la celebración de las fiestas católicas en el pueblo central. Pero se advierte que este tipo de cargos festivo-rituales es rechazado por la presencia de los protestantes, bajo el argumento religioso de que se debe dejar de servir a los vecinos y buscar el establecimiento de las "autoridades 
nuestras" (Idem: 134). Ello, según el mismo autor, supone "la búsqueda por constituir autoridades propias independientes de estos dos polos: el pueblo y las autoridades tradicionales" (Idem: 136). Lo que quiere decir que en esta región se experimenta abiertamente el agotamiento de la legitimidad de las autoridades del ayllu, tanto como de los vecinos de pueblo.

En suma, al presente, el corregidor resume la tradición jurídica del tiempo prehispánico, caracterizada por su drasticidad y flexibilidad al mismo tiempo. También sintetiza el horizonte de la justicia colonial y republicana, con la aplicación de "actas de entendimiento", sanciones económicas, entre otras. Lo que sugiere que el corregidor representa el punto de articulación o el entrecruzamiento de fuerzas jurídicas multitemporales. Definitivamente, nos encontramos ante un espacio que explicita el pluralismo legal.

\subsection{Crisis de la autoridad}

El inciso II del Art. 109 de la actual CPE (Reforma constitucional de Bolivia de 1994) insiste en que los corregidores son autoridades administrativas departamentales en los cantones. Sin embargo, en la práctica, estos espacios han sido cooptados hacia el sistema de autoridades indígenas o campesinas, con diversas atribuciones y competencias. En otros casos son aún remozamientos de conductas coloniales que estructuran las repúblicas de españoles e indios, pero también podemos advertir procesos que explicitan el agotamiento de estos dos esquemas estructurantes.

Con la Ley de Participación Popular de 1994, también se ha erosionado la jurisdicción y competencias del corregidor. A través de los gobiernos municipales, dicha ley privilegia la sección de provincia, sobre todo por su acceso a la administración de los recursos económicos. Basta citar su artículo $1^{\circ}$, cuyo texto reza: "La presente Ley reconoce, promueve y consolida el proceso de participación popular, articulando a las comunidades indígenas, campesinas y urbanas, en la vida jurídica, política y económica del país...".

En cotidianidad, ello supone el franco debilitamiento de la autoridad del corregidor, debido a la desestructuración y reestructuración territoriales. Como ejemplo, basta citar que su competencia 
en el campo económico ha sido cooptada por los municipios, precisamente a raíz de la referida ley.

\section{CONCLUSIONES}

Revisar la historia de los antecesores de la actual autoridad del corregidor nos condujo a las siguientes conclusiones:

El corregidor de indios dista del corregidor de españoles en cuanto a su concepción se refiere. El segundo era un oficio comprado desde España. En cambio, los corregidores de indios eran nombrados dentro el mismo territorio de las colonias y de acuerdo a la cantidad de indígenas que las poblaban (cf. Larson 1979). Precisamente, esta diferencia supuso que la autoridad del corregidor de indios resumiera conceptos indígenas, sobre todo incaicos y españoles, por cuya característica de hibridación, en parte, es posible explicar la controversia y el debate que generaron su implante en las altas esferas de la administración colonial.

Dejamos en claro que, durante la Colonia, el corregidor de indios tuvo competencias políticas, económicas, administrativas y jurídicas. Dada su condición de máxima autoridad, representaba uno de los principales artificios de la división político-administrativa; era su principal atribución convertir a los pueblos prehispánicos en "indios", imponiendo políticas de homogeneización y de desestructuración territorial. En lo judicial, se caracterizó por llevar a cabo actuaciones antijurídicas, ilegales y clandestinas; en las que poco o nada valían el fuero o los derechos de justicia. Son estos antecedentes los que, en 1780, dan lugar a rebeliones indígenas que sacudieron los cimientos de la sociedad colonial, por ser el responsable mayor de hacer efectivo el reparto de mercancías en proporciones desmesuradas entre los indios $y$, consiguientemente, el advenimiento de su crisis institucional.

En la República, la autoridad del corregidor es connatural con el nuevo modelo de división político-administrativa, en particular el cantón; consecuentemente, con menor jerarquía. Aunque, según las leyes republicanas, tenía limitadas atribuciones, en la práctica asumió competencias políticas, jurídicas, económicas y territoriales, pero con carácter represivo hacia el mundo indígena. Bajo su 
jurisdicción se encontraban las autoridades naturales, sobre las que imprimía impunes castigos, de acuerdo a sus deseos y los de la oligarquía -principalmente terrateniente- de manera autocrática. Eran los principales mediadores entre los indígenas y el Estado republicano. Desde sus inicios, el cargo era asumido fundamentalmente por los vecinos de pueblo, en cuya virtud es atinente la caracterización de Rasnake como "autoridades vecinos" (1989: 86), precisamente porque eran elegidos por el grupo de vecinos y legitimados por el Gobierno central a través de los subprefectos. Siendo una función de "servicio público", no percibían remuneración alguna, por lo que se puede explicar lo despótico de su accionar en el campo de la administración de justicia, teniendo el poder de sancionar, castigar con trabajos públicos y hasta enviar a prisión a los infractores.

También hemos evidenciado la erosión, control y distorsión de la justicia indígena con la implantación de la dialéctica de culpabilidad, inocencia y castigo selectivos, lejos de aquellos principios de reconciliación propios. Sin embargo, pese a tales características, las comunidades, ayllus y markas procuraron copar estos espacios de poder, en una franca postura de descolonización, sobre todo desde el mundo ritual del derecho (cf. Fernández 2000), que es un espacio clandestino que permite la salvaguarda de los principios estructurantes o su reelaboración hacia nuevas formas jurídicas, donde lo dominante sufre un proceso de reconceptuación. De esta manera, nos encontramos frente a una especie de síntesis de distintos referentes.

Tanto en la Colonia como en la República, el corregidor se encuentra ligado a las actuaciones de despotismo, exacción e ilegitimidad para con el mundo indígena, así como a sus consecuentes sublevaciones. Son por demás elocuentes la rebelión indígena de principios de 1780 y las posteriores rebeliones y masacres de Taraqu y Jesús de Machaqa, en 1920 y 1921 respectivamente. Ello nos lleva a concluir que la violencia estatal ilegítima se constituye en otro mecanismo de legitimidad en contextos signados por formas $y$ maneras coloniales.

Tras el proceso de la revolución nacional de 1952, la forma de poder o dominación de la autoridad del corregidor cambiará sustantivamente. En algunas regiones, como La Paz, por la de una 
fuerza cohesiva y creadora de consenso, sobre todo en los casos de disputa individual o pública, pues al haber sufrido un paulatino proceso de comunalización hacia el poder indígena, toda vez que ha sido asumido como cabeza de las autoridades locales, su proceder habrá de tener legitimidad en los hechos jurídicos. En otros lugares, como Potosí, el agotamiento de la autoridad del corregidor representa también el de las autoridades indígenas, y consecuentemente la búsqueda de construir autoridades independientes con mayor legitimidad y consenso. Independientemente de tales particularismos, resume principios jurídicos y políticos prehispánicos, caracterizados por su drasticidad y flexibilidad, ya que al mismo tiempo representan tanto el horizonte de la justicia colonial y republicana reinterpretadas en sus propios paradigmas como la aplicación de "sentencias suspendidas en forma de multas con montos bastante altos, como mecanismo para controlar la reincidencia, a manera de candados jurídico-culturales" (Idem: 339).

Finalmente, se visibiliza también la utilización de los medios estatales como mecanismos jurídicos auxiliares, lo cual podría entenderse como la mejor expresión de un "entrecruzamiento de fuerzas jurídicas multitemporales" (Idem: 340) que parecen causar continuos efectos de cambio y regeneración de los principios y valores normativos indígenas. 


\section{Bibliografía}

Testimonio oral de Tomás Colque (ayllu Mikaya)

Fuentes documentales del Archivo de La Paz - EP 1922

Constituciones políticas del Estado de 1826, 1831, 1834, 1839, 1961, 1994.

División Política Administrativa de la República de Bolivia 1996.

Recopilación de leyes de los Reynos de las Indias MDCCXXXXI.

Recopilación de leyes de los Reynos de las Indias MDCCXXXXI, tomo II.

BAYLE, Constantino

1945 El protector de indios, CSIC/EEHA, Sevilla.

BLocH, Ernest

1971 "Efectos políticos del desarrollo desigual", en El concepto de ideología, Lenk, Kurta compiladores, Amorrortu, España. 


\section{MARCELO FERNÁNDEZ OSCO}

CONDARCO MORALES, Ramiro

1965 Zárate, el 'temible Willka'. Historia de la rebelión indígena de 1899 en la República de Bolivia, Talleres Gráficos Bolivianos, La Paz.

CHOQUE, Roberto y Esteban Ticona

1996 Jesús de Machaqa: La marka rebelde. Sublevación y masacre de 1921, Vol. 2, CEDOIN/CIPCA, La Paz.

FERNÁNDEZ Osco, Marcelo

1996 El poder de la palabra: Documento y memoria oral en la resistencia de Waquimarka contra la expansión latifundista (1874-1930) (tesis de licenciatura en sociología), UMSA, La Paz.

2000 La ley del Ayllu. Práctica de jach'a justicia y jisk'a justicia (justicia mayor y justicia menor) en comunidades aymaras, PIEB, La Paz.

Frías MendozA, Víctor $\mathrm{H}$.

2002 Mistis y mokochinches. Mercado, evangélicos y politica local en Calcha, Ed. Mama Huaco, La Paz.

GolTE, Jürgen

1980 Repartos y rebeliones: Túpac Amaru y las contradicciones de la economía colonial, Instituto de Estudios Peruanos, Lima.

ITURRICHA, Agustín

1909 Leyes numerada y compiladas de la República boliviana, y comentadas, tomo I, Talleres Gráficos La Prensa, La Paz.

LARSON, Brooke

1979 "Caciques, Class Structure and the Colonial State in Bolivia", Nova Americana 2: 197-235.

GACETA OFICIAL de Bolivia

1903 Ley de Organización Política. 
PASADO Y PRESENTE DE LA AUTORIDAD DEL CORREGIDOR

1994 Ley de Participación Popular.

LOHMANN VILLENA, Guillermo

1957 El corregidor de indios en el Perú bajo los Austrias, Ediciones Cultura Hispánica, Madrid.

MAMANI, Carlos

1991 Taraqu 1866- 1935: Masacre, guerra y renovación en la biografía de Eduardo Nina Qhispi, Aruwiyiri, La Paz.

MEDINACELI, Ximena

1986 Comunarios y yanaconas. Resistencia pacífica de los indios de Omasuyos (siglo XIX) (tesis de licenciatura en historia), UMSA, La Paz.

MURO OREJÓN, Antonio

1989 Lecciones de historia del derecho hispano-indiano, Porrúa, México.

O'PHELAN GODOY, Scarlett

1976 "El Sur Andino a fines del siglo XVIII: ¿cacique o corregidor?", en Allpanchis 11/12: 17-32.

RASNAKE, Roger

1989 Autoridad y poder en los Andes: Los kuraqhuna de Yura, HISBOL, La Paz.

RIVERA, Silvia

1991 "Pedimos la revisión de límites: Un episodio de incomunicación de castas en el movimiento de caciques-apoderados de los Andes bolivianos: 1919-1921", en Reproducción y transformación de las sociedades andinas siglos XVIXX, tomo II, Colección 500 años, Abya-Yala, Quito.

\section{SALOMÓN, Frank}

1990 "Culto a los ancestros y resistencia frente al Estado de Arequipa entre los años 1748 y 1754", en Steve J. Stern 


\section{MARCELO FERNÁNDEZ OSCO}

(comp.), Resistencia, rebelión y conciencia campesina en los Andes siglos XVIII al XX, IEP, Lima.

SARMIENTO DONATE, Alberto

1988 De las leyes de Indias (antología de la recopilación de 1681), Secretaría de Educación Pública, México.

TALLER DE HISTORIA Oral Andina (THOA)

1984 El indio Santos Marka T'ula, cacique principal de los ayllus del Qallapa y apoderado general de las comunidades originarias de la República, THOA, La Paz.

THOMSON, Sinclair

1996a "Quiebre del cacicazgo y despliegue de los poderes en Sica Sica, 1740-1771", en Xavier Albó (Comp.), La integración Sur Andina cinco siglos después, Centro de Estudios Regionales Andinos "Bartolomé de las Casas", Cusco.

1996b Colonial Crisis Community, and Andean Self-rule: Aymara Politics in the Age of Insurgency (Eighteenth-Century La Paz) (tesis doctoral en historia), University of Wisconsin - Madison.

Valle de Siles, María Eugenia del

1990 Historia de la rebelión de Tupac Katari, 1781-1782, Ed. Don Bosco, La Paz.

Wamán PUMA de Ayala, Felipe

1992/1614 El primer nueva corónica y buen gobierno, Siglo XXI, México. 